\title{
Gestational stress, placental norepinephrine transporter and offspring fertility
}

\author{
Beatriz Piquer, Jose L Fonseca and Hernán E Lara \\ Laboratory of Neurobiochemistry, Faculty of Chemistry and Pharmaceutical Sciences, Universidad de Chile, \\ Independencia, Santiago, Chile \\ Correspondence should be addressed to HE Lara; Email: hlara@ciq.uchile.cl
}

\begin{abstract}
Chronic cold stress produces adrenergic overload that can affect fetal development. The placental norepinephrine transporter (NET) clears norepinephrine (NE) from both maternal circulation and the fetus during gestation. If this system fails, NE clearance can be reduced, leading to high fetal exposure to NE. The main aim of this study was to determine the changes in NET expression during gestation and their relationship with the functional capacity of NET to transport NE under stressful conditions. Additionally, this study correlated these findings with the reproductive capacity of 2nd-generation progeny. Pregnant rats were subjected to chronic cold stress at $4^{\circ} \mathrm{C}$ for $3 \mathrm{~h}$ each day throughout their pregnancies. We found that exposure of pregnant rats to sympathetic stress caused the following effects: increased NE and corticosterone levels throughout pregnancy, decreased capacity of the placenta to clear NE from the fetus to the mother's circulation, altered NET protein levels depending on the sex of the fetus and increased placental and body weights of pups. For the first time, we also described the disrupted fertility of progeny as adults. Increased NE plasma levels during pregnancy under sympathetic stress conditions correlated with decreased NET functionality that provoked changes in the development of progeny and their fertility in adulthood.

Reproduction (2017) 153 147-155
\end{abstract}

\section{Introduction}

Stress has emerged as one of the most important challenges in maintaining the body's homeostasis. Among developmental stages, the gestation period is particularly sensitive; gestational stress can cause permanent modifications during the postnatal development of newborns (fetal programming), predisposing them to diseases in adulthood (Godfrey \& Barker 2000, 2001). Many stressful fetal exposures can provoke responses in adult rats depending on their sex; for example, although a high-fat diet of a gestating mother causes endothelial dysfunction in the progeny of both sexes, it leads to arterial hypertension only in females. If the stressful stimulus is under-nutrition, arterial hypertension occurs only in males (Grigore et al. 2008, 2009). Cold stress produces chronic adrenergic overload that can affect the development of fetuses (Benedict et al. 1979, Pacak et al. 1998, Goldstein \& Kopin 2008). We previously used this cold stress paradigm in gestating rats, and we found that female newborn rats presented delayed follicular development and low response of the ovaries to folliclestimulating hormone ( $\mathrm{FSH}$ ) either in the capacity to stimulate cyclic adenosine monophosphate (cAMP) or to stimulate the transition from primary to secondary follicles (Barra et al. 2014). This delayed follicular development also affected the age of puberty and post-puberty estrous cycles, suggesting that gestational stress permanently affected the reproductive function of first-generation female rat progeny. If this finding were true, it would be very likely that placental tissue would be a target of increased sympathetic tone during gestation. In this regard, in the sympathetic nerves, norepinephrine (NE) concentrations are regulated by the activity of the norepinephrine transporter (NET), which clears NE from maternal circulation and the fetus during gestation. In fact, high levels of NET have been documented in mammalian placental tissue (including from humans) (Melikian et al. 1994, Shearman \& Meyer 1998). If this system fails, NE clearance would decrease, which could lead to high fetal exposure to NE. This effect has been observed in sheep (Gu \& Jones 1986). Given that this mechanism could be present in placental tissue during pregnancy, the main aim of this study was to determine the changes in NET expression during gestation and their relationship with the functional capacity of NET to transport NE under stressful conditions. As a marker of reproductive function, we also wanted to correlate these data with the reproductive capacity of 2 nd-generation progeny. The results of this study clearly indicated that placental changes in NET were involved in gestational stress modification of the reproductive functions and fertility of progeny. 


\section{Materials and methods}

\section{Animals}

Sprague-Dawley rats weighing 250-300g were maintained at $20^{\circ} \mathrm{C}$ with a 12 -h light and $12-\mathrm{h}$ darkness cycle. Water and food were provided ad libitum. For the selection of the dams, we used pre-paired selections from non-sister dams of the same age (age difference of 2-3 days between each) from the same breeding facility. No significant differences between groups were found in the homogeneity test of variance. The estrous cycling activity of the rats was monitored with vaginal smears. On an afternoon during the proestrus phase, the rats were mated, and pregnancy was confirmed the following morning by checking for a vaginal plug. We randomized 35 pregnant rats into two groups of 18 control rats and 17 stressed rats (Fig. 1).

The control rats were maintained at room temperature during their entire pregnancy, and the stressed rats were moved to a cold room at $4{ }^{\circ} \mathrm{C}$ for $3 \mathrm{~h}$ each day during their entire pregnancy. All of the experimental procedures complied with national guidelines (CONICYT Guide for the Care and Use of Laboratory Animals) and were approved by the Bioethics Committee of the Faculty of Chemistry and Pharmaceutical Sciences at the Universidad de Chile (Protocols number: CBE2013-17 and CBE2012-18). Every effort was made to minimize the quantity of animals used and their suffering.

\section{Study on prenatal rats}

All the animals were killed by decapitation with a guillotine, and plasma was collected in tubes with EDTA and metabisulfite and stored at $-80^{\circ} \mathrm{C}$ to determine catecholamine and corticosterone. We randomized 21 pregnant rats into two groups of 11 control rats and 10 stressed rats (Fig. 1A). One group of 5 control rats and 5 stressed rats was killed at 15 days of gestation, and another group of 6 control rats and 5 stressed rats was killed at 19 days of gestation. The rats' placentas were frozen at $-80^{\circ} \mathrm{C}$ or were immediately used to assess the functionality of the placental NET.

\section{Fertility study}

We randomized 14 pregnant rats into two groups of 7 control rats and 7 stressed rats. Their pups were considered as first generation (Fig. 1B). First-generation rats (control or stressed) were maintained in control conditions until they were 3 months old. At that point, one group of 20 control rats and another group of 20 stressed rats were set apart, and both groups were checked for activity of the estrous cycle to determine the day in which proestrus occurred. On an evening in the proestrus phase, female rats were mated with males of proven fertility. On the following morning, female rats were checked for a vaginal plug. If the check was positive, the rat was classified as being on day 0 of pregnancy. If the rats did not show signs of proestrus (mostly the stressed rats) during a two-week period, they were placed with the males every night for two weeks and were checked every morning for a vaginal plug. If no vaginal plug were detected after this case, the female rats would not be mated anymore and were assumed to be infertile. The offspring from this phase of the study were considered to be secondgeneration progeny.

After 4 days, some of the control newborn rats $(n=11)$ were used to assess the weight of the control group, and the remaining rats $(n=55)$ were used after birth (day 1$)$ for other studies related to the development of the heart to minimize the number of tested animals, as recommended by the Local Bioethical Committee. In the case of newborn stressed rats $(n=48)$, all of them continued with the experimental protocol.

\section{Determination of ${ }^{3} \mathrm{H}-\mathrm{NE}$ incorporation by NET}

The functional response of the NET was determined by measuring the incorporation of ${ }^{3} \mathrm{H}-\mathrm{NE}$ by the placentas of the offspring. The placentas from male and female pups were incubated under two conditions: at $37^{\circ} \mathrm{C}$ on Krebs buffer for $60 \mathrm{~min}$ with $2 \mu \mathrm{Ci} / \mathrm{mL}^{3} \mathrm{H}-\mathrm{NE}$ with or without cocaine. We previously did a time curve at 10,20 and $60 \mathrm{~min}$ to ensure that we were at equilibrium. Equilibrium was established at $20 \mathrm{~min}$. This quantification with the use of cocaine (a specific inhibitor of monoamine reuptake (Greiner et al. 2008)) provided us
A
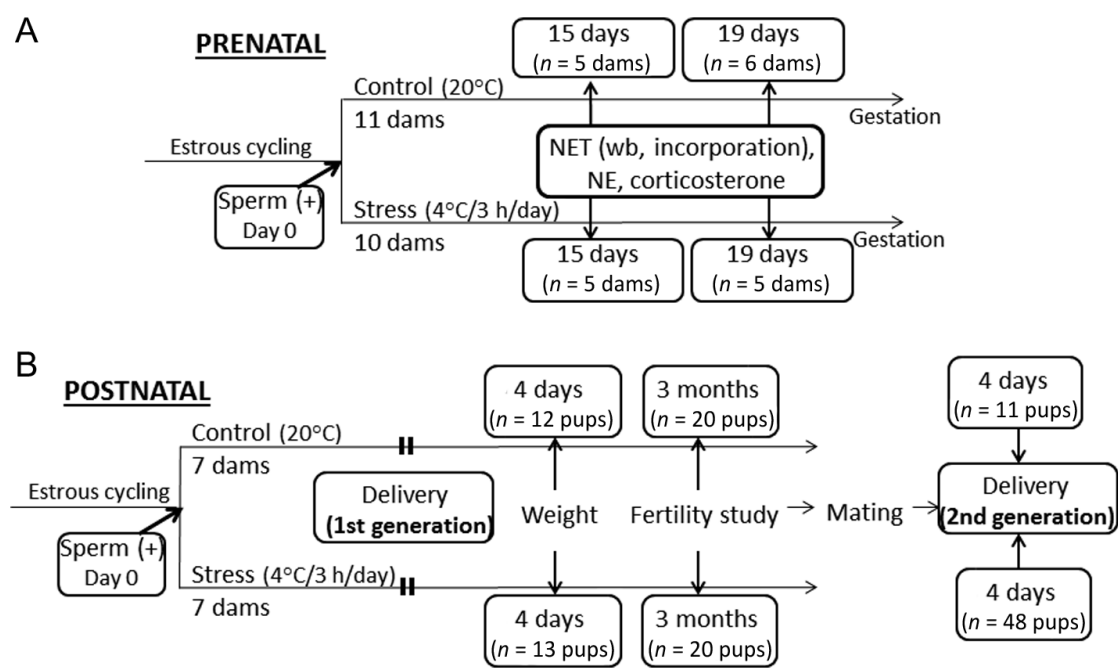

Figure 1 Experimental design of the groups of rats. In (A) the distribution of pups used for the prenatal studies is shown and in (B) the distribution of females during the postnatal stage to obtain the first and second generation of rats is shown (fertility study). 

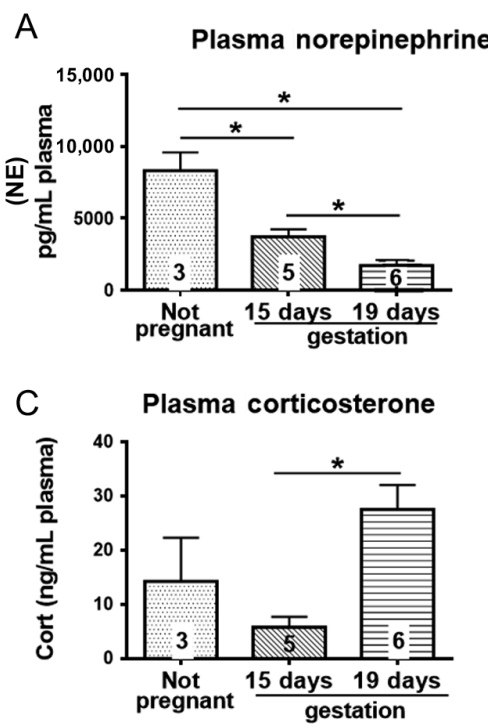

B
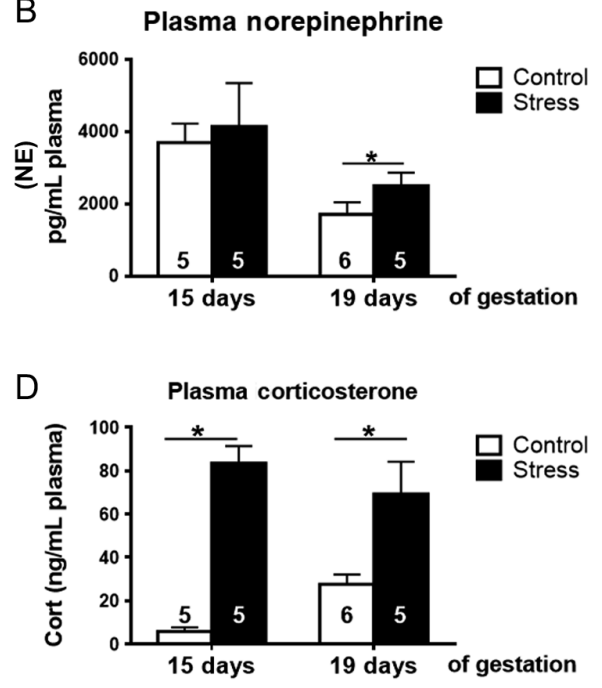

Figure 2 Norepinephrine and corticosterone plasma levels in rats. (A) Norepinephrine and (C) corticosterone plasma levels in pregnant (15 and 19 days of gestation) and nonpregnant control rats. (B) Norepinephrine and (D) corticosterone plasma levels in pregnant (15 and 19 days of gestation) controls and stressed rats. The results correspond to the mean \pm S.E.M. of the number of rats shown in each graph. ${ }^{*} P<0.05$. with specific information about the in vitro incorporation of NE through the cocaine-sensitive NET.

\section{Determination of plasma levels of norepinephrine by HPLC}

The alumina adsorption process was performed on $100 \mu \mathrm{L}$ of the plasma, which was previously stored at $-80^{\circ} \mathrm{C}$, and catecholamines were eluted with $100 \mu \mathrm{L}$ of $0.2 \mathrm{M}$ PCA. This obtained elution was injected into the HPLC for the plasma norepinephrine determination, as previously described (Dorfman et al. 2003).

\section{Determination of plasma levels of corticosterone}

Corticosterone levels were determined using an enzyme immunoassay according to the manufacturer's instructions (Alpco Diagnostic, Windham, NH, USA). The intra-assay variation was $<8.3 \%$, and the inter-assay variation was $<12.4 \%$. The minimal detectable value was $4.1 \mathrm{ng} / \mathrm{mL}$.

\section{Protein isolation}

Frozen placental tissue from one female and one male fetus per dam was used at 19 days of gestation. At 15 days of gestation, there was no sexual dimorphism; thus, placentas were selected randomly.

The placentas of pups at 15 and 19 days of gestation were homogenized with RIPA buffer (Tris- $\mathrm{HCl} \mathrm{pH} 7.210 \mathrm{mM}$, Triton X-100 1\%, NaCl $150 \mathrm{mM}$, SDS $0.1 \%$ ) with a glassglass homogenizer on ice and were centrifuged at $12,000 \mathrm{~g}$ for $20 \mathrm{~min}$ at $4{ }^{\circ} \mathrm{C}$. The protein concentration was measured according to the Bradford method (Bradford 1976).

\section{Electrophoresis and western blotting}

The samples $(15 \mu \mathrm{g}$ of proteins) were heated for $5 \mathrm{~min}$ at $95^{\circ} \mathrm{C}$. Electrophoresis was performed with $10 \%$ SDS-PAGE gels for $90 \mathrm{~min}$. Thereafter, the separated proteins were blotted on nitrocellulose. The blots were then incubated with blocking buffer ( $5 \%$ skim-milk powder and TBST, consisting of Tris-Base $0.224 \%$ (p/v), $\mathrm{NaCl} 0.8 \%(\mathrm{p} / \mathrm{v})$, and Tween $200.1 \%(\mathrm{v} / \mathrm{v})(\mathrm{pH} 7.6)$, for $1 \mathrm{~h}$ at room temperature, followed by incubation with 1:1000 anti-SLC6A2 rabbit antibody (Sigma-Aldrich) in blocking buffer overnight at $4^{\circ} \mathrm{C}$. After 3 washes for $5 \mathrm{~min}$ with TBST, incubation with horseradish peroxidase-conjugated anti-rabbit antibodies (Abcam) was conducted at a dilution of 1:10,000 for $1 \mathrm{~h}$ at room temperature. The blots were then washed 3 times with TBST for $5 \mathrm{~min}$. The proteins were detected with an EZ-ECL Kit (Biological Industries Israel Beit Haemek Ltd., Kibbutz Beit Haemek, Israel). The immunostaining intensity was measured by densitometry. In all of these cases, GAPDH was used as a housekeeping gene (1:40,000 anti-GAPDH, Sigma-Aldrich). These experiments were repeated three times, and under these conditions, the western blot analysis presented a $20 \%$ variability.

\section{Placental incorporation of ${ }^{3} \mathrm{H}-\mathrm{NE}$}

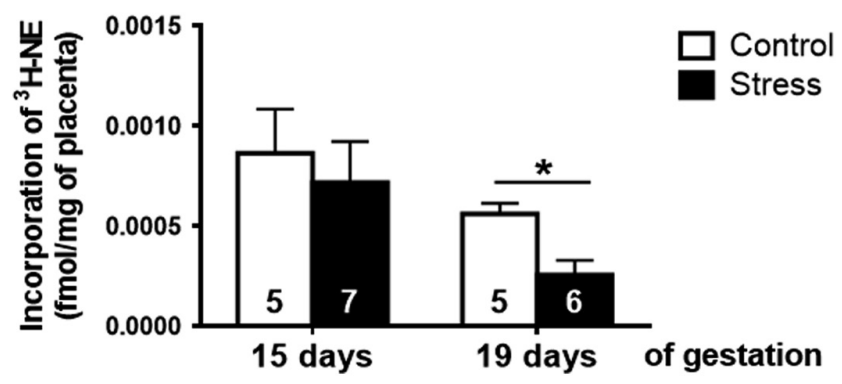

Figure 3 Incorporation of ${ }^{3} \mathrm{H}-\mathrm{NE}$ by norepinephrine transporter in the placenta at 15 and 19 days of gestation in controls and stressed rat pups. The results correspond to the mean \pm S.E.M. of the number of rats shown in the graph. ${ }^{*} P<0.05$. 

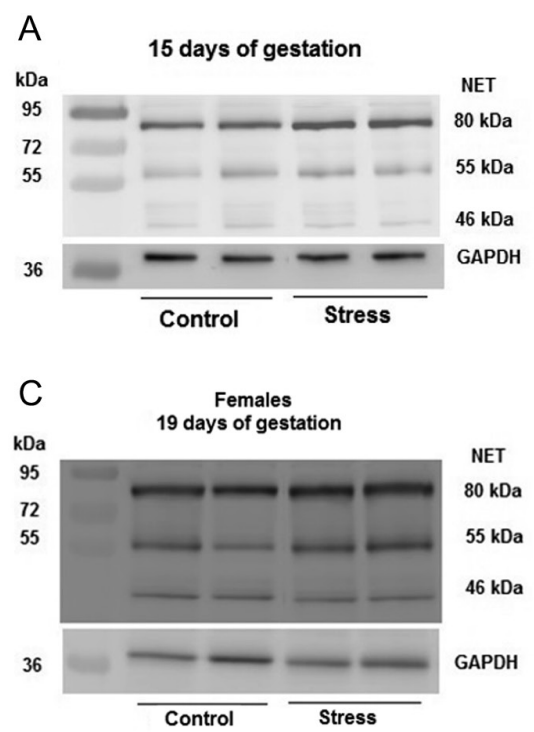

\section{Statistical analyses}

The data were expressed as the mean \pm S.E.M. values. To determine significant differences among multiple groups, we used a one-way ANOVA, followed by the Newman-Keuls post hoc test to check for differences between pairs of data. Previously, each of the groups was analyzed to verify the homogeneity of variance. To analyze the fertility of the secondgeneration rats, a chi-square test was applied. The comparison was statistically significant at $P<0.05$.

\section{Results}

\section{Effect of gestational stress on plasma norepinephrine}

Gestating rats were exposed to a temperature of $4^{\circ} \mathrm{C}$ for $3 \mathrm{~h}$ each day during the entire gestation period, and the concentration of NE in the plasma was determined (Fig. 2). In Fig. 2A, we compared the NE plasma levels in control non-pregnant rats with those in 15- and 19-day gestating rats. A continuous decrease in NE was found in the control gestating rats, attaining lower NE levels close to delivery. When we compared these levels with the NE levels found in age-matched stressed rats during gestation, we did not find changes in NE at 15 days of gestation, but there was an increase in NE levels at day 19 of gestation (Fig. 2B).

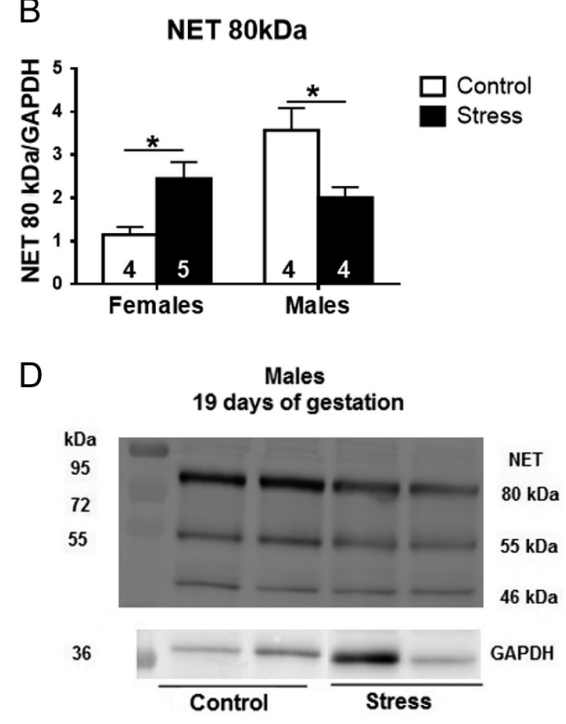

Figure 4 Norepinephrine transporter protein in the placenta of controls and stressed rat pups. (A) Representative membrane of the western blot analysis of NET's three bands $(80 \mathrm{kDa}$, $55 \mathrm{kDa}$ and $46 \mathrm{kDa}$ ) obtained from the placentas at 15 days of gestation of controls and stressed rat pups. (B) Quantification of NET's $80 \mathrm{kDa}$ protein from the placentas at 19 days of gestation in controls and stressed rat pups. Representative membrane of the western blot analysis of NET's from the placentas at 19 days of gestation from (C) females, (D) male controls and stressed rat pups. The results correspond to the mean \pm S.E.M. of the number of three independent experiments. The number of rats is shown in the graph. ${ }^{*} P<0.05$.

\section{Effect of gestational stress on plasma corticosterone levels}

Although it was previously proven that the cold stress paradigm used in this work did not affect corticoid plasma levels (Benedict et al. 1979), studies on the effect of this stress paradigm during gestation had not been conducted. During a normal pregnancy, we found increased corticosterone plasma levels at day 19 of gestation, but no changes at day 15 (Fig. 2C). During gestational stress, corticosterone plasma levels increased from day 15 of gestation (Fig. 2D), and they remained high until the end of gestation.

\section{Effect of gestational stress on placental norepinephrine transporter (NET)}

Because of the changes in NE plasma levels during gestational stress, it was important to assess the functionality of the transporter and NET concentrations. In Fig. 3, the changes in the capacity of placental tissue were shown to incorporate NE specifically in vitro through the cocaine-sensitive NE transporter. The results corresponded to placentas from both sexes because we did not find changes of the incorporation of NE by female and male placentas or placental and

Table 1 Effect of cold stress exposure during gestation on the numbers of pups of the first generation.

\begin{tabular}{lll}
\hline & Control & Stress \\
\hline $\begin{array}{l}\text { Number of pups/litter } \\
15 \text { days of gestation }\end{array}$ & $14.4 \pm 1.2(n=5$ mothers $)$ & $13.4 \pm 0.8(n=5$ mothers $)$ \\
19 days of gestation & $13.3 \pm 1.0(n=6$ mothers $)$ & $13.8 \pm 0.9(n=5$ mothers $)$ \\
19 days of gestation/sex & Females: $7.0 \pm 0.7$ & Females: $7.0 \pm 0.4$ \\
& Males: $6.3 \pm 0.6$ & Males: $6.8 \pm 0.9$ \\
\hline
\end{tabular}

The results correspond to the mean \pm S.E.M. of the number of pups/litters of the gestating rats, shown in parenthesis. 
Table 2 Effects of cold stress exposure during gestation on the length of gestation and number of newborn rats of the first generation.

\begin{tabular}{lll}
\hline & Control & Stress \\
\hline Gestation (days) & $21.6 \pm 0.3(n=7$ mothers $)$ & $21.9 \pm 0.1$ ( $n=7$ mothers $)$ \\
Number of newborns/litter & $14.4 \pm 0.3$ & $11.7 \pm 1.6$ \\
Number of newborns separated by sex & Females: $7.6 \pm 1.0$ & Females: $5.8 \pm 0.5$ \\
& Males: $6.8 \pm 1.1$ & Males: $5.9 \pm 0.9$ \\
\hline
\end{tabular}

The results correspond to the mean \pm S.E.M. of the number of days of gestation or the number of newborn rats/litter.

body weight of the fetus (details as Supplementary information).

We did not find differences in the incorporation of NE at 15 days of gestation in the placental tissue obtained from the controls and stressed rats. However, at day 19 of gestation, a $50 \%$ decrease in the capacity of the placental tissue to incorporate NE was found in the placental tissue of stressed rats, compared with the controls.

To verify whether this change was a result of the synthesis of the transporter protein, we quantified the amount of protein by western blot analysis. The analysis showed three principal bands of sizes 80, 55 and $46 \mathrm{kDa}$ (Fig. 4A). These three isoforms

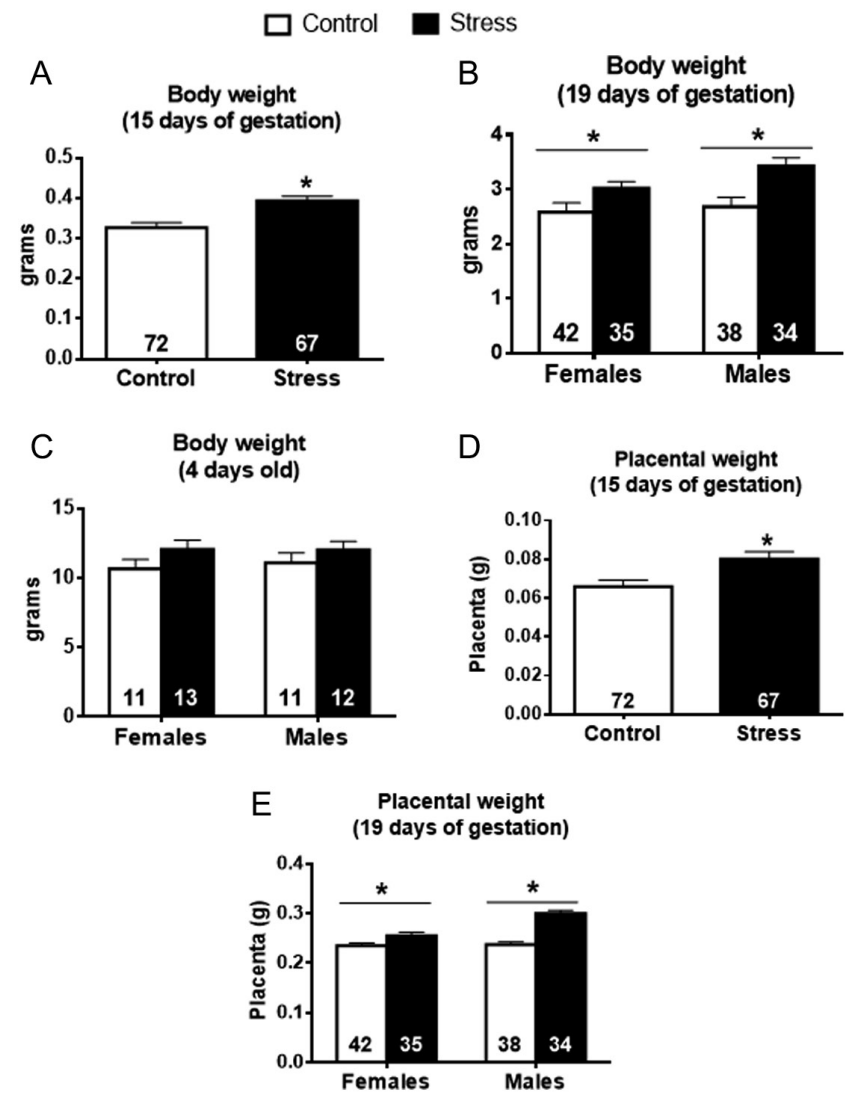

Figure 5 Body and placental weights of rat pups. Body weights of controls and stressed rat pups at (A) 15 days of gestation, (B) 19 days of gestation and (C) 4 days. Placental weights of controls and stressed rat pups at (D) 15 days of gestation and (E) 19 days of gestation. The results correspond to the mean \pm S.E.M. of the number of rats shown in each graph. ${ }^{*} P<0.05$. were previously demonstrated to be proteins with different degrees of glycosylation. The $80 \mathrm{kDa}$ was the completely glycosylated mature isoform, and the $47 \mathrm{kDa}$ was the immature isoform (Melikian et al. 1994, Jayanthi et al. 2004). We did not find the effects of gestational stress on any of the three isoforms at 15 days of gestation (data not shown, representative gel is shown in Fig. 4A). At 19 days of gestation, however, sex-dependent changes in NET were found. The placental tissue of female fetuses from stressed mothers presented a higher level of NET protein, compared with controls (Fig. 4B), and the placental tissue from male fetuses presented a $50 \%$ decrease in the amount of protein. Gels that are representative of both samples are shown in Fig. 4C and D.

\section{Effects of gestational stress on placental weight and pups}

There was no modification in the day of delivery or in the total number of pups between the controls and stressed mothers (Tables 1 and 2). At day 15 of gestation, we found increased weight of the pups from stressed rats, compared with those from control non-stressed mothers (Fig. 5A). Unfortunately, at this early age, we could not verify sex dimorphism to separate the fetuses by sex. The 72 pups from the 5 control pregnant rats and the 67 pups from the 5 stressed pregnant rats corresponded to the total pups (males and females). At day 19 of gestation, however, females were able to be differentiated from males, indicating the number of pups from 6 control pregnant rats and 5 stressed pregnant rats. The increased weight of pups from stressed rats was maintained at day 19 of gestation (Fig. 5B) but was not present in 4-dayold pups (Fig. 5C), which was independent of sex. An increase in the weight of placental tissue at days 15 and 19 of gestation (Fig. 5D and E) was also found. At day 4 , there was no mortality of either the controls or stressed newborn rats.

\section{Effects of gestational stress on the fertility of the female progeny when adults}

No difference was found in the number of newborn rats from the first generation (i.e., those exposed to cold stress), but a decrease in second-generation 

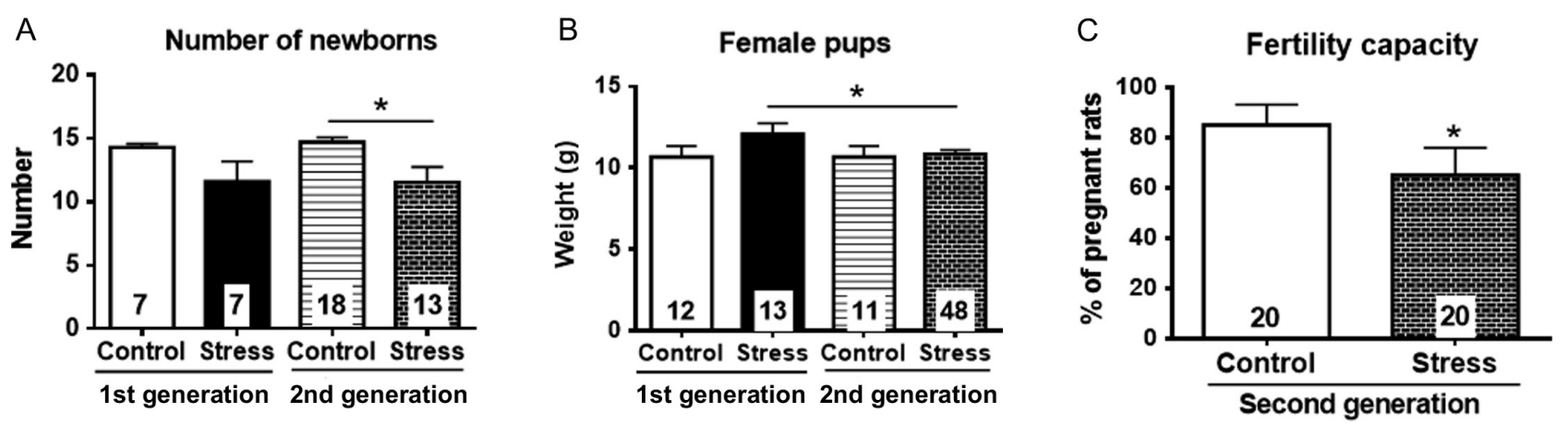

Figure 6 Physiological impact of gestational stress on the second generation of rats. (A) Number of newborn rat controls in the first and second generations. In the graph, the number of pregnant rats in each group is shown. (B) Body weight at 4 days of female newborns rats. (C) Fertility of the second generation of stressed rats. The results are shown as the mean \pm S.E.M. of the number of rats in each graph. The results were analyzed with a one-way ANOVA followed by the Newman-Keuls post hoc test. Brackets show significance between groups. ${ }^{*} P<0.05$. In the case of fertility, the results were analyzed with a chi-square test.

rats appeared when first-generation female rats were mated with fertile males (Fig. 6A). In the analysis, the weight of female newborn rats decreased in the second generation (Fig. 6B). The most important finding was that second-generation rats presented decreased fertility when they were mated with fertile males (Fig. 6C). In this case, we used 20 controls and 20 stressed rats to examine fertility; we found that 18 of the 20 control rats became pregnant, but only 13 of the 20 stressed rats became pregnant.

\section{Discussion}

We found that exposing pregnant rats to sympathetic stress affected the placental transport of $\mathrm{NE}$, leading to a decreased capacity of the placenta to clear NE from the fetus to the mother's circulation. For the first time, we also described the disrupted fertility of progeny as adults.

\section{NE plasma levels during gestation and the effect of stress}

Cold stress without hypothermia is a form of sympathetic stress in which the ACTH axis is not compromised (Benedict et al. 1979, Pacak et al. 1998, Goldstein \& Kopin 2008); thus, the effects found in this work could be attributed to overexposure of the fetus to increased NE levels. We previously used chronic exposure to cold as an experimental tool to stimulate the sympathetic nerves in the ovaries of adult rats for 3, 4 or 8 weeks (Dorfman et al. 2003, Bernuci et al. 2008, 2012). In addition, we used this stress paradigm in pregnant rats to study the impact on the ovarian function of their progeny (Barra et al. 2014). Here, the main objective of this paper was to determine whether cold stress modified NE plasma levels of pregnant rats and whether changes in the NET expression of placental tissue could provide greater insight on the detrimental effects on reproductive function previously found by our laboratory (Barra et al. 2014). The continuous decrease in NE plasma levels found in non-pregnant rats on the 15th and 19th days of the pregnant rats' gestation could be due to increased corticosterone levels in the control rats. This increase was also found during human pregnancy (Wintour et al. 1978). Independent of this finding, cold exposure during gestation modified the pattern of changes in NE plasma levels. There was an increase in NE at day 19 of gestation despite the increased plasma levels of corticosterone, which were described as negative regulators of catecholamine biosynthesis (Dupouy et al. 1975). Glucocorticoids decreased the proteolysis of phenylethanolamine n-methyltransferase (PNMT), an enzyme that produces adrenaline, and thus increased adrenaline synthesis with a concomitant decrease in NE (Wong et al. 1992).

During gestation, the fetus adapts to the environmental changes to which the mother is exposed. If exposure to these external conditions is chronic, the fetus develops all of its organs to prepare for the external milieu. This rapid adaptation occurs in only one generation; thus, it is much more rapid than genetic changes (Hales \& Barker 2001, Kajantie 2006, Phillips et al. 2006, Wells 2007, Cottrell \& Seckl 2009), and it could induce permanent changes in cellular structure, organ physiology and metabolism that translate into a predisposition to cardiovascular, metabolic and endocrine diseases as adults (Godfrey \& Barker 2000, 2001). In this regard, many studies performed in animals have demonstrated that short periods of exposure to excess or limited food, independent of the age of fetal development, has deleterious effects on long-term development (Wu et al. 2004). This finding reflects the concept that nutrient availability during gestation could be one of the most important factors to determine the risk of diseases in adulthood (Langley-Evans 2007). Protein restriction in Wistar rats during gestation and lactation increased the risk of cardiac fibrosis in adulthood (Lim et al. 2006), 
and these data were supported by findings of low levels of cardiac $\beta_{1}$-adrenergic receptors, reduced cardiac basal rhythm and lower levels of insulin receptors. In addition, isoproterenol delayed the compensatory response to recover cardiac rhythm, suggesting that prenatal exposure to protein restriction in the mother was directly linked to an increase in cardiac disease (Fernandez-Twinn et al. 2006). In the same manner, prenatal exposure to glucocorticoids (to mimic stress) decreased the weight of newborn pups and increased blood pressure (Seckl \& Holmes 2007). The stage of gestation during which the stress was applied was also important. Stress was more harmful when applied during days 1-11 than when applied during the second half of gestation or over the entire gestation period, as indicated by decreased numbers and weights of newborns and increased neonatal deaths (Guo et al. 1993). Although our stress paradigm did not affect the number of newborn pups, they did lead to larger placentas. Additionally, even when keeping mothers' diet and weight constant (data not shown), the weights of the pups throughout the pregnancy were greater. Regarding the sympathetic stress paradigm used in this work, increased plasma levels of NE could result in vasoconstriction of the uterine arteries, leading to failure in the invasion of trophoblasts ( $\mathrm{Na}$ et al. 2013). This could likely explain the delayed development of neonatal ovaries under this stress paradigm (Barra et al. 2014). Rats' ovaries develop during the last 5 days of pregnancy, i.e., the same stage in which the clearest changes in catecholamines were found.

One of the roles of the placenta is to maintain low levels of monoamines by clearing them from the uteroplacental circulation. The placenta achieves this by expressing high levels of monoamine transporters to remove catecholamines from the plasma and amniotic fluid (Hansson et al. 2007). Pregnant women with preeclampsia have lower levels of NET (Bottalico et al. 2004), which could result in increased catecholamine levels in fetal blood, as demonstrated in sheep. When catecholamines were administered to gestating sheep, they demonstrated high efficacy in clearing increased levels of adrenaline from the fetus, but when applied to a long-term study, increased levels of adrenaline in fetal blood were found (Gu \& Jones 1986). This observation strongly suggested that prolonged stimuli, such as chronic stress, could affect the fetus and program physiological functions that are expressed in adulthood. This finding was especially important given the increased norepinephrine levels found during the rats' gestation and the NET transporter's decreased capacity to mobilize ${ }^{3} \mathrm{H}$-norepinephrine.

Because this study's stress paradigm effectively produced increased NE plasma levels, we correlated these data with the capacity of placental tissue to transport ${ }^{3} \mathrm{H}-\mathrm{NE}$. The incorporation of NE into placental tissue could be non-specific to many transporters present in the placenta that could be used by NE. Because we analyzed the cocaine-sensitive transporter (only for NET (Greiner et al. 2008)), we can strongly infer that the decreased capacity to transport NE in the placental tissue of both male and female pups was due to a functional problem in the transporter's capacity or a decreased number of proteins in the plasma membrane. It is possible that these effects were related to a molecular mechanism that controls the electrochemical gradient of $\mathrm{Na}^{+}$. This allowed the intracellular $\mathrm{Na}^{+}$ (Mandela \& Ordway 2006) to accumulate and was thus dependent on $\mathrm{Na}^{+} / \mathrm{K}^{+}$ATPase, which regulates the $\mathrm{Na}^{+}$ gradient in cells. During placental failure, which occurs during preeclampsia, a vasoconstrictor cardiotonic (marinobufagenin) is produced that inhibits $\mathrm{Na}^{+} / \mathrm{K}^{+}$ ATPase activity, decreasing the functionality of NET (Bagrov et al. 2007, Puschett et al. 2010).

A novel, unexpected observation was the sex difference in the expression of the NET transporter under stressful conditions. In the placental tissue of male pups, NET protein expression was higher. Under stress, however, NET protein expression increased in the placental tissue of female pups, whereas that of male pups decreased. To our knowledge, this study was the first time that a sex difference was described in placental NET, but there have been many examples of sex-associated changes caused by in utero stimuli. For example, undernutrition during gestation caused hypertension only in male pups. In contrast, increased fat in the diets of pregnant rats produced endothelial dysfunction in male and female pups but hypertension only in females (Grigore et al. 2008, 2009). Gestating rats exposed to warmth, light and restraint in a multiple stress paradigm showed preferential effects on the cardiovascular response of their female progeny (Igosheva et al. 2004). Further studies are needed to explain this last observation.

One of the most important observations of this study was the impact that gestational sympathetic stress had on the reduced capacity of second-generation female rats to be fertile after mating with fertile males. Furthermore, these data supported our previous study in which after the same gestational stress paradigm, first-generation newborn female rats presented delayed development of primary and secondary follicles and a lower response to $\mathrm{FSH}$ and $\beta$-adrenergic receptor agonists to stimulate secondary follicle development, hence delaying puberty (Barra et al. 2014). Here, we found that these rats had damaged fertility. It is likely that these effects were due to epigenetic modifications provoked by chronic exposure to sympathetic overload of the pups during intrauterine development. The impact of this exposure on male development remains to be established. 


\section{Conclusion}

Increased NE plasma levels during pregnancy under sympathetic stress conditions correlated with decreased NET functionality that provoked changes in the development of progeny and their fertility in adulthood.

\section{Declaration of interest}

The authors declare that there is no conflict of interest that could be perceived as prejudicing the impartiality of the research reported.

\section{Funding}

This work was supported by Fondecyt grant 1130049 (to H E L) and Conicyt grant for doctoral thesis 21120077 (to B P). This work was completed in partial fulfillment of the requirements of a PhD degree in Pharmacology of B P at the U.Ch.

\section{References}

Bagrov YY, Manusova NB, Frolova EV, Egorova IA, Kashkin VA, Tapilskaya NI, Fedorova OV \& Bagrov AY 2007 Endogenous sodium pump inhibitors, diabetes mellitus and preeclampsia preliminary observations and a hypothesis. Pathophysiology 14 147-151. (doi:10.1016/j.pathophys.2007.09.003)

Barra R, Cruz G, Mayerhofer A, Paredes A \& Lara HE 2014 Maternal sympathetic stress impairs follicular development and puberty of the offspring. Reproduction 148 137-145. (doi:10.1530/REP-14-0150)

Benedict CR, Fillenz M \& Stanford C 1979 Noradrenaline release in rats during prolonged cold-stress and repeated swim-stress. British Journal of Pharmacology 66 521-524. (doi:10.1111/j.1476-5381.1979.tb13689.x)

Bernuci MP, Szawka RE, Helena CV, Leite CM, Lara HE \& AnselmoFranci JA 2008 Locus coeruleus mediates cold stress-induced polycystic ovary in rats. Endocrinology 149 2907-2916. (doi:10.1210/en.20071254)

Bernuci MP, Leite CM, Barros P, Kalil B, Leoni GB, Del Bianco-Borges B, Franci CR, Szawka RE, Lara HE \& Anselmo-Franci JA 2012 Transitory activation of central and ovarian norepinephrine systems during cold stress-induced polycystic ovary in rats. Journal of Neuroendocrinology 25 23-33. (doi:10.1111/j.1365-2826.2012.02373.x)

Bottalico B, Larsson I, Brodszki J, Hernandez-Andrade E, Casslén B, Marsál K \& Hansson SR 2004 Norepinephrine transporter (NET), serotonin transporter (SERT), vesicular monoamine transporter (VMAT2) and organic cation transporters (OCT1, 2 and EMT) in human placenta from pre-eclamptic and normotensive pregnancies. Placenta 25 518-529. (doi:10.1016/j.placenta.2003.10.017)

Bradford MM 1976 A rapid and sensitive method for the quantitation of microgram quantities of protein utilizing the principle of protein-dye binding. Analytical Biochemistry 72 248-254. (doi:10.1016/00032697(76)90527-3)

Cottrell EC \& Seckl JR 2009 Prenatal stress, glucocorticoids and the programming of adult disease. Frontiers in Behavioral Neuroscience 3 19. (doi:10.3389/neuro.08.019.2009)

Dorfman M, Arancibia S, Fiedler JL \& Lara HE 2003 Chronic intermittent cold stress activates ovarian sympathetic nerves and modifies ovarian follicular development in the rat. Biology of Reproduction 68 2038-2043. (doi:10.1095/biolreprod.102.008318)

Dupouy JP, Coffigny H \& Magre S 1975 Maternal and foetal corticosterone levels during late pregnancy in rats. Journal of Endocrinology 65 347-352. (doi:10.1677/joe.0.0650347)

Fernandez-Twinn DS, Ekizoglou S, Wayman A, Petry CJ \& Ozanne SE 2006 Maternal low-protein diet programs cardiac beta-adrenergic response and signaling in 3-mo-old male offspring. American Journal of Physiology: Regulatory Integrative and Comparative Physiology 291 R429-R436. (doi:10.1152/ajpregu.00608.2005)

Godfrey KM \& Barker DJ 2000 Fetal nutrition and adult disease. American Journal of Clinical Nutrition 71 (5 Supplement) 1344S-1352S.

Godfrey KM \& Barker DJ 2001 Fetal programming and adult health. Public Health Nutrition 4 611-624. (doi:10.1079/PHN2001145)

Goldstein DS \& Kopin IJ 2008 Adrenomedullary, adrenocortical, and sympathoneural responses to stressors: a meta-analysis. Endocrine Regulations 42 111-119.

Greiner M, Paredes A, Rey-Ares V, Saller S, Mayerhofer A \& Lara HE 2008 Catecholamine uptake, storage, and regulated release by ovarian granulosa cells. Endocrinology 149 4988-4996. (doi:10.1210/en.2007-1661)

Grigore D, Ojeda NB \& Alexander BT 2008 Sex differences in the fetal programming of hypertension. Gender Medicine $\mathbf{5}$ (Supplement A) S121-S132. (doi:10.1016/j.genm.2008.03.012)

Grigore D, Ojeda NB \& Alexander BT 2009 Sex differences in the fetal programming of cardiovascular disease. Gender Medicine 5 S121-S132. (doi:10.1016/j.genm.2008.03.012)

Gu W \& Jones CT 1986 The effect of elevation of maternal plasma catecholamines on the fetus and placenta of the pregnant sheep. Journal of Developmental Physiology 8 173-186.

Guo A, Nappi RE, Criscuolo M, Ficarra G, Amram A, Trentini GP, Petraglia F \& Genazzani AR 1993 Effect of chronic intermittent stress on rat pregnancy and postnatal development. European Journal of Obstetrics and Gynecology and Reproductive Biology 51 41-45. (doi:10.1016/0028-2243(93)90189-J)

Hales CN \& Barker DJ 2001 The thrifty phenotype hypothesis. British Medical Bulletin 60 5-20. (doi:10.1093/bmb/60.1.5)

Hansson SR, Bottalico B, Amer-Wahlin I, Marsál K \& Ley D 2007 Increased fetal blood pressure response to maternal norepinephrine after pharmacological inhibition of norepinephrine uptake in pregnant sheep. Acta Paediatrica 96 650-654. (doi:10.1111/j.16512227.2007.00262.x)

Igosheva N, Klimova O, Anishchenko T \& Glover V 2004 Prenatal stress alters cardiovascular responses in adult rats. Journal of Physiology $\mathbf{5 5 7}$ 273-285. (doi:10.1113/jphysiol.2003.056911)

Jayanthi LD, Samuvel DJ \& Ramamoorthy S 2004 Regulated internalization and phosphorylation of the native norepinephrine transporter in response to phorbol esters. Evidence for localization in lipid rafts and lipid raft-mediated internalization. Journal of Biological Chemistry 279 19315-19326. (doi:10.1074/jbc.M311172200)

Kajantie E 2006 Fetal origins of stress-related adult disease. Annals of the New York Academy of Sciences 1083 11-27. (doi:10.1196/ annals.1367.026)

Langley-Evans SC 2007 Metabolic programming in pregnancy: studies in animal models. Genes and Nutrition 2 33-38. (doi:10.1007/s12263007-0005-x)

Lim K, Zimanyi MA \& Black MJ 2006 Effect of maternal protein restriction in rats on cardiac fibrosis and capillarization in adulthood. Pediatric Research 60 83-87. (doi:10.1203/01.pdr.0000220361.08181.c3)

Mandela P \& Ordway GA 2006 The norepinephrine transporter and its regulation. Journal of Neurochemistry 97 310-333. (doi:10.1111/ j.1471-4159.2006.03717.x)

Melikian HE, McDonald JK, Gu H, Rudnick G, Moore KR \& Blakely RD 1994 Human norepinephrine transporter. Biosynthetic studies using a site-directed polyclonal antibody. Journal of Biological Chemistry 269 12290-12297.

Na KH, Choi JH, Kim CH, Kim KS \& Kim GJ 2013 Altered expression of norepinephrine transporter and norepinephrine in human placenta cause pre-eclampsia through regulated trophoblast invasion. Clinical and Experimental Reproductive Medicine 40 12-22. (doi:10.5653/ cerm.2013.40.1.12)

Pacak K, Palkovits M, Yadid G, Kvetnansky R, Kopin IJ \& Goldstein DS 1998 Heterogeneous neurochemical responses to different stressors: a test of Selye's doctrine of nonspecificity. American Journal of Physiology 275 R1247-R1255.

Phillips DIW, Jones A \& Goulden PA 2006 Birth weight, stress, and the metabolic syndrome in adult life. Annals of the New York Academy of Sciences 1083 28-36. (doi:10.1196/annals.1367.027)

Puschett JB, Agunanne E \& Uddin MN 2010 Marinobufagenin, resibufogenin and preeclampsia. Biochimica et Biophysica Acta 1802 1246-1253. (doi:10.1016/j.bbadis.2010.02.005) 
Seckl JR \& Holmes MC 2007 Mechanisms of disease: glucocorticoids, their placental metabolism and fetal 'programming' of adult pathophysiology. Nature Clinical Practice Endocrinology and Metabolism 3 479-488. (doi:10.1038/ncpendmet0515)

Shearman LP \& Meyer JS 1998 Norepinephrine transporters in rat placenta labeled with [3H]nisoxetine. Journal of Pharmacology and Experimental Therapeutics 284 736-743.

Wells JC 2007 The thrifty phenotype as an adaptive maternal effect. Biological Reviews of the Cambridge Philosophical Society 82 143-172. (doi:10.1111/j.1469-185X.2006.00007.x)

Wintour EM, Coghlan JP, Oddie CJ, Scoggins BA \& Walters WA 1978 A sequential study of adrenocorticosteroid level in human pregnancy. Clinical and Experimental Pharmacology and Physiology 5 399-403. (doi:10.1111/j.1440-1681.1978.tb00690.x)
Wong DL, Lesage A, Siddall B \& Funder JW 1992 Glucocorticoid regulation of phenylethanolamine $\mathrm{N}$-methyltransferase in vivo. FASEB Journal 6 3310-3315.

Wu G, Bazer FW, Cudd TA, Meininger CJ \& Spencer TE 2004 Maternal nutrition and fetal development. Journal of Nutrition $1342169-2172$.

Received 9 June 2016

First decision 14 July 2016

Revised manuscript received 5 October 2016

Accepted 4 November 2016 